\title{
Effect of the CNT Quality in CNT/Al2024 Composites
}

\author{
R. Pérez-Bustamante ${ }^{1}$, F. Pérez-Bustamante ${ }^{1,2}$, P. Amézaga-Madrid ${ }^{1}$, I. Estrada-Guel ${ }^{1}$, M. Miki- \\ Yoshida $^{1}$ and R. Martínez-Sánchez ${ }^{1}$ \\ 1. Centro de Investigación en Materiales Avanzados (CIMAV), Miguel de Cervantes No. 120, C.P. \\ 31109, Chihuahua, Chihuahua, México \\ 2. Universidad Autónoma de Chihuahua (UACH), Av. Escorza No. 900. Zona Centro. C.P. 31000, \\ Chihuahua, Chihuahua, México
}

Carbon nanotubes (CNTs) have attracted the attention of the scientific community due to their potential applications for the development of novel technologies in different areas, such as medicine, energy, optoelectronic, and the capability to be used as material reinforcement for the development of materials with an enhanced mechanical performance. A wide variety of methods have been used in the nanotubes synthesis. One of them is the chemical vapor deposition (CVD) for a massive production of CNTs where the variation in the synthesis conditions can lead to the production of different quality (lengths, diameter and crystallinity) of CNTs. Even though the mechanical properties of single-walled nanotubes (SWCNTs) present a superior mechanical performance in comparison with multi-walled nanotubes (MWCNTs), MWCNTs can be easily produced at massive scale by CVD systems [1]. This offers the opportunity for their use in the production of a wide variety of composites.

In this concern, CNTs has been used mainly in polymer-based composites, however, a steadily increase in the research of their effect on the production of metal-based composites has been carried out. Of particular interest in the development of metal matrix composites, it is the use of aluminum-based composites [2], due to the light weight and mechanical properties of the aluminum and its alloys [3].

In this work, CNTs were produced by CVD with two different synthesis conditions. CNT obtained were used as reinforcement for the production of the composites. Composites were fabricated by mechanical alloying in a high-energy mill Spex 8000M. Milling time was set to $5 \mathrm{~h}$. CNTs were added in $5.0 \mathrm{wt}$.\% concentration in an A12024 powder matrix prepared from elemental powders. All experimental runs were performed under an argon atmosphere. Methanol was added as process control agent in order to avoid excessive agglomeration of particles. Powders were cold consolidated under a pressure of 850 MPA. The consolidated samples were sintered at $500^{\circ} \mathrm{C}$, under an argon atmosphere during $2 \mathrm{~h}$, with a cooling a heating rate of $5^{\circ} \mathrm{C} / \mathrm{min}$.

CNTs were characterized by Raman spectroscopy and transmission electron microscopy (TEM), whilst the composites were microstructurally characterized by means of X-ray diffraction (XRD), Raman spectroscopy and scanning electron microscopy (SEM). The mechanical behavior of the composites was evaluated through a Vickers microhardness test with $150 \mathrm{~g}$ of load and a dwell time of $15 \mathrm{~s}$. As reference, an unreinforced 2024 aluminum alloy was produced according to the previous synthesis conditions.

Fig. 1 shows Z-contrast STEM micrographs of the two samples of nanotubes (A and B samples) obtained from the CVD synthesis. Fig. 1a shows a CNT with a diameter in the range of $\approx 30 \mathrm{~nm}$ whilst Fig. $1 \mathrm{~b}$ presents a nanotube with an outer diameter of $300 \mathrm{~nm}$. 
Fig. 2 shows the results of the effect of the A and B samples of CNTs on the microstructural and mechanical behavior of CNT/A12024 composites. It can be observed that for $5 \mathrm{~h}$ of milling the amount the metal-carbon bonds do not present a significant different according to Raman and XRD results, however, the mechanical behavior evaluated by microhardness shows an increase of about of 40 hardness units in the composite reinforced with CNTs of the A sample $\left(A_{c}\right)$ in comparison with the composite reinforced with CNTs of the B sample $\left(\mathrm{B}_{\mathrm{c}}\right)$. This indicates that even though the presence of aluminum carbides particles remains constant in the reinforced composites, a better mechanical bond between the CNTs of A quality and Al matrix is presented over the composites reinforced with CNTs of the B quality.

\section{References}

[1] C.J. Lee et al, Chem. Phys. Lett., 359 (2002) p. 109-114.

[2] R. George et al, Scripta Mater., 53 (2005) p. 1159-1163.

[3] A. Javadi et al, Fullerenes Nanotubes Carbon Nanostruct., 21 (2013) p. 436-447.

[4] Thanks to W. Antúnez-Flores, P. Piza-Ruiz and E. Torres-Moyé for their technical assistance.
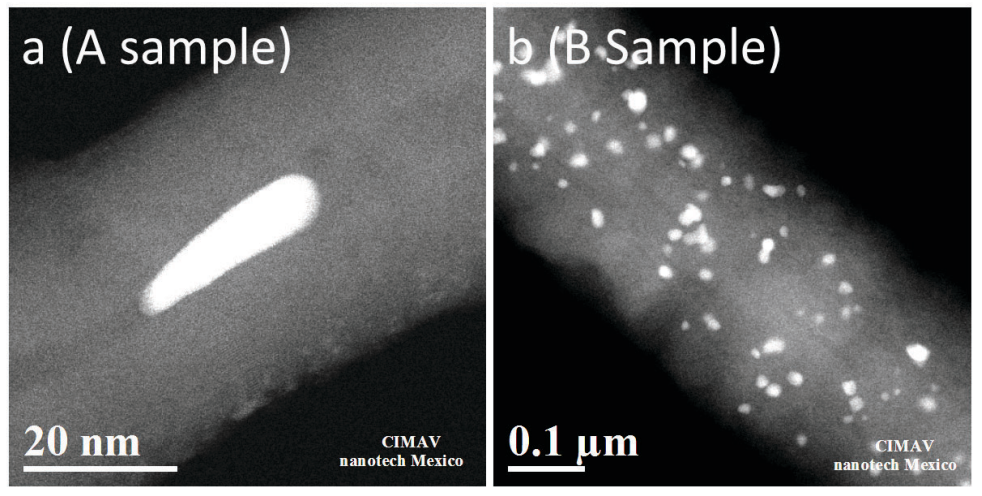

Figure 1. Z-contrast STEM micrographs of CNTs produced by CVD. CNTs with diameter of about (a) 30 and (b) $300 \mathrm{~nm}$ are obtained.
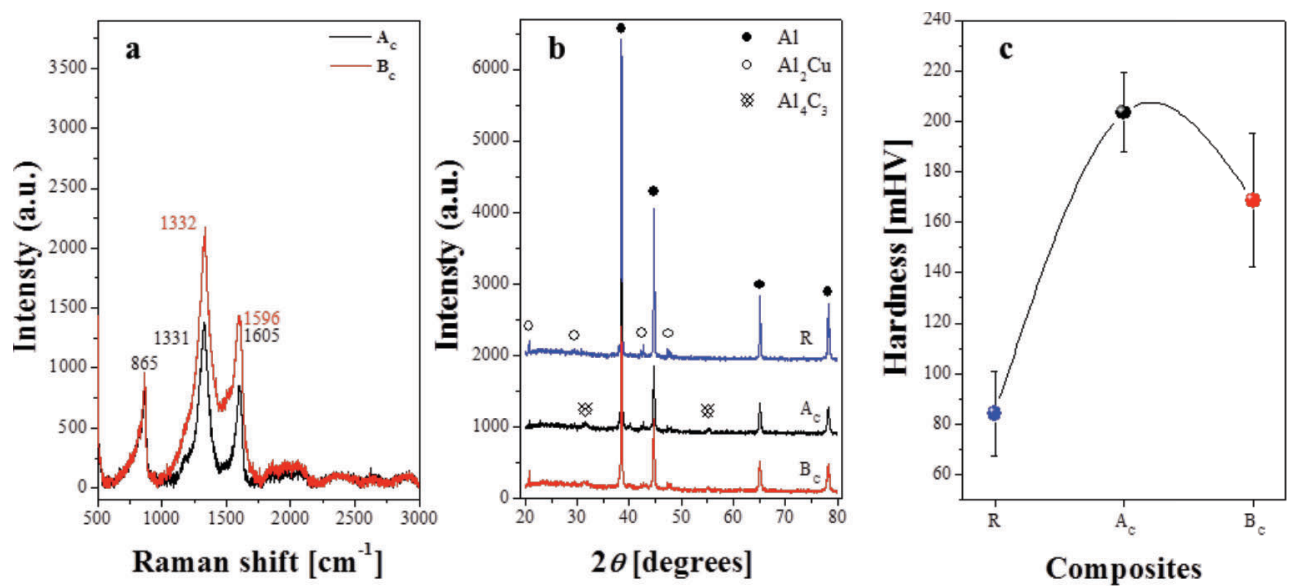

Figure 2. Results of CNT/Al composites (a) Raman spectroscopy, (b) X-Ray diffraction and (c) Vickers microhardness. 